\title{
Um modelo de gestão da informação para aprendizagem organizacional em projetos empresariais
}

\begin{abstract}
Nabor Alves Monteiro
\end{abstract}
\begin{abstract}
Mestre em Ciência da Informação pela PUCCampinas; Docente da graduação e da especialização da Universidade Guarulhos; Docente da graduação da Universidade São Francisco.
\end{abstract}

Orandi Mina Falsarella

Doutor em Engenharia Mecânica pela UNICAMP; Docente da gradução de do Programa de Mestrado em Ciência da Informação da PUCCampinas.

O objetivo deste trabalho foi apresentar um modelo de gestão da informação de modo a se obter aprendizagem organizacional em projetos. Trata-se de um estudo teórico no qual procurou-se enfatizar a interface entre a Ciência da Informação com o campo de conhecimentos da Área de Administração que trata de projetos. A pesquisa conclui que uma adequada gestão da informação na gestão de projetos pode favorecer a aprendizagem organizacional, com conseqüente formação de uma substancial base de conhecimentos.

Palavras-chave: Gestão da informação; Gestão de projetos; Sistema de informação; Aprendizagem organizacional.

\section{A model of information management on project management to organizational learning}

The objective of this study was is to propose a model of information management in such a way that it leads to an organizational learning in project management. This research is a theoretical study that emphasizes the interface between the Information Science and the Administration field that deals with projects. It has reached the conclusion that an adequate information 
management applied to project management may favor the organizational learning and, consequently, form a substantial knowledge base.

Key-words: Information management; Project management; Information system; Organizational learnin.

Recebido em 07.12.2006 Aceito em 24.04.2007

\section{Considerações iniciais}

O ambiente vivido pelas empresas atualmente apresenta-se caracterizado por mudanças aceleradas. Novas tecnologias surgem a cada dia, a economia está globalizada, a concorrência é extremamente acirrada, diversas exigências são geradas por normas e legislações e existe a preocupação com o meio ambiente e com a responsabilidade social. Este cenário de constantes e rápidas mutações representa para as empresas ameaças e oportunidades. Com o objetivo de se adaptarem a este ambiente, as empresas são obrigadas a implementarem mudanças no seu processo de negócio. É neste contexto que despontam os projetos, pois a implantação de mudanças foge das atividades rotineiras de uma empresa. Como a implementação de mudanças não faz parte da gestão da rotina, surge a necessidade da gestão de projetos que, por sua vez, necessita de informações para ser gerido. Além disso, o projeto também produz informações com valor agregado. E, tanto as informações prospectadas, quanto as informações produzidas, se bem geridas, podem levar à aprendizagem organizacional. Assim a gestão da informação desponta como um importante fator de competitividade nas empresas, pois a empresa que aprende adquire maturidade e tem maior chance de sobrevivência num ambiente atribulado.

Esta pesquisa surgiu em função de uma lacuna existente na literatura que diz respeito à relação entre a gestão de projetos e a Ciência da Informação, mais especificamente no tocante à gestão da informação em projetos. Trata-se de uma pesquisa teórica que tem como preocupação o desenvolvimento de um modelo de gestão da informação que possa ser aplicado na gestão de projetos. O artigo faz uma breve descrição da gestão de projetos e da gestão da informação, para em seguida fazer uma junção destas duas áreas do conhecimento.

\section{Os projetos empresariais}

Os projetos existem desde a antiguidade. Se olharmos para grandes empreendimentos como a construção das pirâmides do Egito, o Êxodo dos hebreus e as grandes navegações, podemos observar que existiu uma gestão de projetos. Apesar de remontar à antiguidade, a gestão de 
projetos só começou a ser sistematizada no século $X X$, com projetos como a construção da bomba atômica e o programa espacial norte americano.

São várias as definições de projetos. Maximiano (1997, p. 20), por exemplo, define projetos como "empreendimentos finitos, que têm objetivos claramente definidos em função de um problema, oportunidade ou interesse de uma pessoa ou de uma organização". Para o PMI - Project Management Institute (PMI-PMBOK, 2004, p. 1) projeto é "um esforço temporário para criar um produto, serviço ou resultado único". Em nosso entendimento, consideramos projetos como um conjunto de atividades concentradas em torno de um objetivo comum, gerado por uma demanda interna ou externa (ou ambas) à organização, que necessita de recursos específicos e que tem início e fim determinados. Um projeto é uma estrutura provisória dentro da organização, ou seja, para a realização de um projeto é montada uma estrutura que será extinta ao final do mesmo.

Nos projetos encontramos diversos componentes que passaremos a descrever a seguir. Todo projeto possui uma série de atividades que devem ser desempenhadas de modo que os objetivos sejam atingidos. Em função dessas atividades os projetos requerem um cronograma e um controle. Os projetos possuem um escopo que na definição de Dinsmore e Silveira Neto (2005, p. 42) "refere-se à definição das fronteiras entre determinadas tarefas, atividades, contratos, atribuições, responsabilidades e missões". Para seu funcionamento, os projetos devem ter uma estrutura organizacional que varia de acordo com o seu porte. Dentro dessa estrutura existe a comunicação. Como qualquer empreendimento organizacional, os projetos necessitam de recursos humanos, financeiros e materiais. Outro componente importante dos projetos é a qualidade. Para Dinsmore e Silveira Neto (2005, p. 141) "os padrões de qualidade são ditados pelos requisitos do projeto, especificações e adequações ao uso". Como parceiro constante em projetos encontramos o risco. Valeriano (1998, p. 63) conceitua risco em projetos como "a possibilidade de ocorrência de um resultado indesejável, como conseqüência de qualquer evento". O resultado de todo projeto é um produto ou serviço.

Todo projeto se caracteriza por ter objetivos definidos, por não ser repetitivo (não existem dois projetos iguais), por ter um período limitado (início e fim bem definidos) e por ocasionar mudanças na organização. Para atendimento dos objetivos uma equipe é designada, e esta pode ser da própria organização ou de fora dela. Uma característica importante dos projetos diz respeito à incerteza quanto aos resultados, o que representa um risco ao seu sucesso. Moresi (2001a, p. 73) afirma que "a incerteza ambiental é determinada pela complexidade e pela variação do ambiente [...] quanto mais complexo e dinâmico for o ambiente, maior será o nível de incerteza ambiental". Sobre a incerteza em projetos, Maximiano (1997) aponta que ela tem a ver com o grau de desconhecimento a respeito de seus resultados, ou a forma de atingi-los, ou ambos.

Os projetos possuem um ciclo de vida que vai da sua concepção até o seu encerramento. Os diversos autores dividem o ciclo de vida de um projeto de forma diferente, dando nomes às fases. Apenas para melhor compreensão deste texto, apresentamos a classificação feita por Dinsmore 
e Silveira Neto (2005). Para estes autores o ciclo de vida de um projeto compreende as seguintes fases:

- Fase de iniciação (concepção): Consiste na identificação de necessidades, estabelecimento de viabilidade, busca de alternativas, elaboração de orçamentos e cronogramas iniciais, nomeação da equipe e preparação da proposta;

- Fase de planejamento: Envolve a realização de estudos e análises, a programação de recursos humanos, materiais e financeiros, o detalhamento do projeto e a preparação do plano do projeto de modo a se obter a aprovação para execução do projeto em instância superior;

- Fase de execução, monitoramento e controle: É a fase do cumprimento das atividades planejadas. Concomitantemente à execução são feitos o monitoramento e o controle das atividades programadas e as devidas correções no curso do projeto;

- Fase de encerramento: É quando o projeto vai chegando ao seu final e as atividades vão sendo concluídas. Inclui o treinamento do pessoal operacional, o comissionamento e a realocação dos membros da equipe do projeto.

Quanto à gestão de projetos, o PMI esclarece que se refere à aplicação de conhecimentos, habilidades, ferramentas e técnicas às atividades do projeto para atender aos seus requisitos (PMI-PMBOK, 2004, p. 8).

Ressaltamos o caráter estratégico dos projetos na atualidade, pois é através deles que as organizações implementam as mudanças necessárias à sua sobrevivência. Essas mudanças, muitas vezes, dizem respeito à busca de inovações tecnológicas que, sem um projeto bem gerido, podem fracassar.

\section{Gestão da informação}

Com a finalidade de contextualizarmos nosso modelo, faremos uma breve discussão sobre informação e conhecimento. Sem menosprezar outras definições, damos ênfase às definições voltadas para a gestão. Dessa forma, começamos citando Aldo Barreto (1994) que define informação como "estruturas significantes com a competência de gerar conhecimento para o indivíduo e seu grupo". O autor enfatiza que a informação está "associada ao conceito de ordem e redução da incerteza". Esta afirmação vem ao encontro da gestão de projetos que tem como uma das características a incerteza. No contexto da gestão, entendemos que informação é um insumo básico para a tomada de decisão e redução de incertezas.

Outro conceito importante é o de conhecimento. McGarry (1999, p. 4) afirma que a informação é a matéria prima da qual se extrai o conhecimento. Para Capurro (2003) "o valor da informação, sua mais valia 
com respeito ao mero conhecimento, consiste precisamente da possibilidade prática de aplicar um conhecimento a uma demanda concreta". Um conceito atual é o de capital intelectual, referindo-se ao conhecimento das pessoas nas empresas. Rezende (2002, p. 126) explica que sob esta óptica, a informação passa a ser vista como um insumo gerador de conhecimento. Garvin et al (1998) conceituam conhecimento organizacional como "a capacidade de executar coletivamente as tarefas que as pessoas não conseguem fazer atuando de forma isolada, tarefas essas projetadas para criar valor para as partes interessadas na organização". Nonaka e Takeuchi (1997, p. 65) classificam o conhecimento em explícito e tácito. O primeiro refere-se ao conhecimento transmissível em linguagem formal e sistemática (codificado). 0 conhecimento tácito é o pessoal, específico ao contexto e, assim, difícil de ser formulado e comunicado. Neste trabalho levamos em consideração apenas o conhecimento explícito, por entendermos que o conhecimento tácito permanece a serviço da organização apenas enquanto o indivíduo nela atua, não sendo, portanto, perene. Na esteira destes conceitos surge a idéia de inteligência. Para Moresi (2001c, p. 119) inteligência é entendida como "a informação como oportunidade, ou seja, o conhecimento contextualmente relevante que permite atuar com vantagem no ambiente considerado". Segundo Tarapanoff et al (2000, p. 91) "a premissa básica para se fazer inteligência é agregar valor à informação, é estruturá-la de modo que a mesma possa ter um valor, uma importância contextual na organização".

Um outro lado importante da informação nas organizações é o monitoramento ambiental, que é um conceito que está ligado à inteligência. Nas palavras de Tarapanoff et al (2000, p. 91),

a inteligência visa, principalmente, a imprimir um comportamento adaptativo à organização, permitindo que estas mudem e adaptem os seus objetivos, produtos e serviços, em resposta a novas demandas do mercado e a mudança no ambiente.

Uma das principais atividades no início de um projeto é a busca da informação. Esta busca tem origem numa necessidade informacional para tentar reduzir as incertezas quanto aos rumos do projeto. Quanto à prospecção, Santos e Beraquet (2001) afirmam que "no contexto da busca de informações, consideradas estratégicas para um propósito, destaca-se a necessidade de uma seleção sistemática e otimizada das informações obtidas". Na opinião de Batista (2004, p. 41) "as informações devem apresentar algumas características de qualidade, oportunidade, conteúdo e qualidade".

Finalmente chegamos ao conceito de gestão da informação. Canongia et al (2001) explicam que "a informação necessita ser gerenciada da mesma forma que os recursos humanos e materiais de uma organização". No entendimento de Davenport (2002) a gestão da informação trata-se de um conjunto estruturado de atividades que incluem o modo como as empresas obtêm, distribuem e usam a 
informação e o conhecimento. Cardoso e Pereira (2005, p. 225) enfatizam que "hoje, a Gestão da Informação é uma arma estratégica para a competitividade global". Em nosso ponto de vista, gestão da informação consiste num conjunto de atividades voltadas à informação como busca, obtenção, tratamento, agregação de valor, armazenamento, disponibilização, uso e retroalimentação. Trata-se, portanto, de um processo cíclico. Assim, podemos falar em um ciclo da gestão da informação o qual parte de uma demanda por informação que conduz a uma busca. Por sua vez a busca gera uma obtenção (informação recuperada). A informação obtida ou é armazenada ou é tratada, ou seja, contextualizada e é agregado valor para em seguida ser armazenada. Esta informação tratada e/ou armazenada fica à disposição para uso. O uso produz novas informações ou gera necessidade de mais informações, recomeçando o ciclo.

Os projetos são grandes consumidores e também grandes produtores de informação. Além disso, apresentam um fluxo intenso de informações durante sua vida. Todo este potencial informativo precisa ser administrado em benefício do projeto. A gestão da informação em projetos tem como funções a prospecção, a seleção, o tratamento, a disponibilização, a circulação e o armazenamento das informações necessárias à elaboração e ao desenvolvimento do projeto. $O$ foco principal da prospecção de informações está no ambiente externo e interno de modo a prover os projetistas com informações de qualidade, para que estes possam elaborar o projeto com o menor grau de incerteza possível. Estas informações devem estar disponíveis no tempo certo, para as pessoas certas e com um custo compatível com o orçamento do projeto. Como os projetos normalmente são compostos por fases com características próprias, a gestão da informação deve acompanhar as particularidades de cada fase, conforme a seguir.

1. Na fase de concepção a gestão da informação tem como preocupação primeira o levantamento das exigências informacionais. Determinadas as necessidades, parte-se para a prospecção, obtenção e disponibilização das informações no nível estratégico. Por ser um estudo preliminar, essas informações são gerais e não específicas, e têm como função fornecer subsídios para decisão quanto a um estudo mais aprofundado sobre a viabilidade ou não do projeto. Nesta fase o uso que se faz da informação é relativo ao estudo de viabilidade do projeto.

2. No planejamento do projeto a gestão da informação deve prover os projetistas de informações mais aprofundadas sobre os ambientes externo e interno, de modo que se possa delinear a execução do projeto. Esta profundidade deve ser adequada às necessidades do projeto, obedecendo aos seguintes parâmetros:

- de custo: que deve estar em acordo com o orçamento do projeto; 
- de qualidade: confiável e adequada ao fim a que se destina;

- de tempo: este parâmetro tem dois aspectos. O primeiro diz respeito ao fornecimento da informação no momento em que dela se necessite e o segundo é relacionado com o prazo de validade da informação que pode afetar sua qualidade.

As informações prospectadas devem ser distribuídas à equipe responsável pelo planejamento do projeto. O uso das informações desta fase se refere ao como, quando e por quem as atividades do projeto serão desempenhadas.

3. Na fase de implementação a gestão da informação pode participar em duas frentes:

- No monitoramento ambiental de modo a detectar mudanças no ambiente que possam afetar o desempenho do projeto. Consiste na busca de informações externas à organização e disponibilização aos tomadores de decisão;

- No controle das atividades que estão sendo desenvolvidas. Refere-se à reunião de informações sobre o andamento do projeto e que deverão estar disponíveis para a equipe.

O uso da informação na fase de implementação diz respeito a decisões sobre correções no curso do projeto e, em casos extremos, decisão sobre a continuidade ou não do projeto.

4. No encerramento do projeto a gestão da informação também deve atuar em duas frentes:

- Na reunião e consolidação das informações produzidas ao longo do projeto;

- Na transferência de informações aos clientes, referentes ao produto do projeto.

A informação usada nesta fase se refere à finalização das tarefas do projeto.

Vale ressaltar que a gestão da informação deve atuar na catalogação e no armazenamento das informações obtidas em função do projeto. Outro destaque a ser dado nesta questão é a importante participação dos sistemas de informação eletrônicos.

São vários os sistemas de informação usados em projetos. Entre eles temos o SIG - Sistema de Informações Gerenciais - que tem como função o apoio às atividades funcionais e aos administradores. Outro sistema que aparece nos projetos é o Sistema de Informação Empresarial, também conhecido como Business Inteligence que, segundo Batista (2004, p. 121): 
Trata-se de um conjunto de ferramentas e aplicativos que oferece aos tomadores de decisão possibilidades de organizar, analisar, distribuir e agir, ajudando a organização a tomar decisões melhores e mais dinâmicas.

Temos o SAD - Sistema de Apoio a Decisão - que apóia a tomada de decisão pelos administradores e analistas, o SPT - Sistema de Processamento de Transação - que fornece suporte às atividades repetitivas vitais e ao pessoal administrativo e o Sistema de Workflow que serve para automatizar tarefas de processamento de informação. Este sistema fornece ao usuário recursos de rastreamento, distribuição, visualização de documentos entre outros. Também usado em projetos temos o SAG - Sistema de Apoio a Grupos - que apóia o pessoal que trabalha em equipe. E, finalmente o Sistema de Conhecimento KMS Knowledge Management System - que, segundo Rezende e Abreu (2006, p. 313) é aquele que manipula ou gera conhecimentos estruturados com a finalidade de contribuir com os seres humanos, com as organizações e com a sociedade. Além desses, há ferramentas para gestão de projetos que fazem o acompanhamento e o controle das atividades do projeto.

\section{Aprendizagem organizacional}

O dicionário Aurélio define aprender como sendo tomar conhecimento, reter na memória, mediante o estudo, a observação ou a experiência. Consta também que aprender é tornar-se apto ou capaz de alguma coisa, em conseqüência de estudo, observação, experiência, advertência, etc. Para Moresi (2001c, p. 119),

o aprendizado é a integração de novas informações em estruturas de conhecimento, de modo a torná-las potencialmente utilizáveis em processos futuros de processamento e de elaboração.

Para Silva et al (2002, p. 131) "informação e conhecimento são ativos indispensáveis para o processo de aprendizagem e inovação tecnológica".

Segundo Davenport (2002, p. 194) "a aprendizagem organizacional se dá não apenas pela obtenção da informação, mas também por sua distribuição a terceiros". Em projetos empresariais a informação precisa circular entre os membros da equipe, tendo como conseqüência a aprendizagem. Na óptica de Rabechini Jr. e Carvalho (2003, p. 3),

no novo cenário competitivo delineado pelo novo milênio, caracterizado pelo ritmo acelerado das mudanças tecnológicas e pela liberalização e volatilização dos mercados globais, as empresas sabem que para competir precisam aprender e gerar conhecimentos.

Garvin (1993), citado por Fleury e Fleury (1995) identifica cinco formas de aprendizagem: 
1. Resolução sistemática de problemas, que contempla os diagnósticos elaborados através de métodos científicos, utilização de dados para a tomada de decisão e recursos de estatística para organizar as informações e inferências.

2. Experimentação, que se refere à procura sistemática e teste de conhecimentos novos pelo método científico. Tem como motivação a busca pela expansão de horizontes.

3. Experiência passada com apoio da sistemática de revisão e avaliação de situações de sucesso e fracasso da própria organização, com a divulgação dos resultados internamente.

4. Circulação de conhecimento pautada pela circulação rápida e eficiente de novas idéias na organização como um todo.

5. Experiências realizadas por outras organizações, o que é feito através da observação do que acontece em outras organizações.

Conforme afirma Choo (2003, p. 232) "a construção do conhecimento organizacional ocorre quando a organização resolve problemas, cria novos produtos ou processos ou dissemina tecnologias e métodos para além de suas fronteiras". Solução de problemas, criação de novos produtos e disseminação de tecnologias e métodos são todos propósitos de projetos.

Para Davenport (2002, p. 194) "a aprendizagem organizacional se dá não apenas pela obtenção da informação, mas também por sua distribuição a terceiros". Em projetos empresariais a informação precisa circular entre os membros da equipe, tendo como conseqüência a aprendizagem. De acordo com Kerzner (2002, p. 18) "os projetos reúnem e vendem conhecimento. [...] Reúne as informações e as transforma em resultado, isto é, formaliza, captura e faz a alavancagem deste conjunto para produzir um ativo de valor ainda maior".

Entendemos que a aprendizagem organizacional se refere à capacidade que uma organização tem de se apropriar do conhecimento que ela mesma busca e produz. Somos de opinião que existem dois tipos de aprendizado organizacional:

1. O aprendizado rotineiro quando os conhecimentos são acumulados empiricamente no dia-a-dia e que são transmitidos às pessoas e registrados em manuais de processos e procedimentos. Não existe a intencionalidade da produção de conhecimento.

2. O aprendizado inovador quando os conhecimentos são produzidos através do método de Gestão do Conhecimento (extração do conhecimento dos membros da organização) ou através de P\&D com um objetivo bem definido. Neste caso fica clara a intenção de produção de conhecimento.

Por este prisma enxergamos todas as organizações como sendo organizações que aprendem, seja de uma forma empírica, seja de uma forma originária de uma busca sistemática. Isto porque, independente do porte da organização, elas vivem num processo contínuo de adaptação ao ambiente se quiserem sobreviver e/ou prosperar. 
A organização que utiliza metodologia de projetos obrigatoriamente precisa buscar informações que, se bem aproveitadas, ou seja, se houver uma gestão adequada da informação, se reverterão em aprendizado. 0 próprio projeto gera uma série de informações que podem se transformar em aprendizado. Tudo isto favorece a elaboração e a gestão de novos projetos. Com a experiência advinda de diversos projetos administrados, a organização vai adquirindo maturidade na área de projetos, o que por sua vez retorna em seu próprio benefício, satisfazendo uma das funções dos projetos que é o de fornecer agilidade para a organização. Daí decorre a importância da gestão da informação em projetos.

O ponto de partida de qualquer projeto é a informação. A idéia de um projeto surge em função de um problema, de uma ameaça ou oportunidade e a administração da organização toma conhecimento de um dos três através da informação. Esta informação, além de ter qualidade também precisa ser muito bem interpretada. A informação da qual se origina um projeto pode ser interna, quando analisa os pontos fortes, fracos e problemas da organização ou externas quando são detectadas ameaças e/ou oportunidades. A falta de informação inviabiliza qualquer projeto.

A informação é um insumo utilizado em todas as fases de um projeto, tanto em termos de coleta para elaboração como o monitoramento ambiental que deve acompanhar o projeto como um todo. Moresi (2001b, p. 93) defende que "o monitoramento ambiental, a aquisição de informações do ambiente externo, deve estar presente no cotidiano das organizações". Em nosso ponto de vista, acreditamos que no caso dos projetos esta máxima deve ser ainda mais enfatizada.

Ao longo de sua existência, toda organização tende a acumular conhecimentos pelo aprendizado organizacional, seja ele de que tipo for. Este acúmulo vai se constituir na base de conhecimentos da organização que, em nosso entendimento, quer dizer um conjunto de conhecimentos adquiridos interna e externamente e registrados em um suporte que pode ser material ou virtual. Nela ficam registradas as melhores práticas, em termos dos sucessos obtidos e também os fracassos. Os sucessos para serem imitados em novos projetos e os fracassos como um alerta a fim de evitar repetições. Esta base de conhecimentos deve ficar disponível para recuperação e uso em momento oportuno.

\section{Modelo conceitual de gestão da informação em gestão de projetos}

Somos de opinião de que para que ocorra a aprendizagem organizacional em projetos se faz necessária a gestão da informação. Esta gestão deve seguir um modelo de modo que seja sistematizada.

De início vamos procurar entender o termo modelo que pode assumir diversas conceituações, conforme o contexto. Considerando o âmbito desta pesquisa encontramos no Dicionário Aurélio que modelo pode ser: (1) objeto a ser reproduzido por imitação; (2) representação em pequena escala de algo que se pretende executar em grande; (3) aquilo 
que serve de exemplo ou norma; molde. Para Sayão (2001, p. 83) "um modelo é uma criação cultural, um 'mentefato', destinada a representar uma realidade, ou alguns de seus aspectos, a fim de torná-los descritíveis qualitativa e quantitativamente e, algumas vezes, observáveis". O modelo conceitual proposto neste trabalho tem como função a reunião do conhecimento acumulado sobre a gestão da informação e a gestão de projetos, de modo que possa ser aplicado para conduzir ao aprendizado organizacional.

Em nossa pesquisa entendemos que modelo conceitual é a representação esquemática de uma estrutura a ser seguida, a qual parte de demandas a serem satisfeitas, para em seguida desencadear ações de modo a se atingir determinados resultados, incluindo nesta estrutura os fluxos necessários. Um modelo tem a virtude de fornecer uma macrovisão, favorecendo o entendimento do todo.

Para descrevermos nosso modelo partimos do princípio de que os projetos podem ser enfocados por uma visão sistêmica, na qual temos:

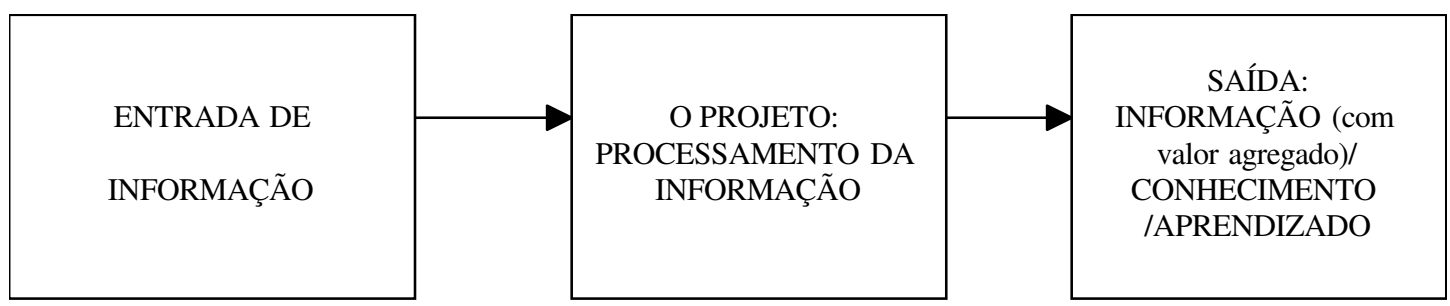

FIGURA 1 - Visão sistêmica de projetos.

Fonte: Dados da pesquisa.

Por esta visão temos que os projetos consomem informação, mas também geram informações com valor agregado que acabam por se transformar em conhecimento e aprendizado. Este novo conhecimento gerado no projeto pode ser revertido em benefício da organização que o empreendeu, formando um círculo virtuoso de geração e aplicação de novos conhecimentos.

Os projetos buscam para uso informações externas além de informações e conhecimentos internos da própria organização. Por sua vez o projeto é um produtor de informações com valor agregado e um gerador de conhecimento que pode beneficiar a organização, se esta tirar proveito do aprendizado decorrente.

O monitoramento ambiental e as informações geradas na organização vão constituindo a base de conhecimentos organizacional. Esta base serve para municiar a concepção e o planejamento do projeto. Durante a fase de implementação as informações vão contribuindo para a formação do produto do projeto. Em decorrência da experiência adquirida vai ocorrendo a formação de conhecimento, que deverá ser incorporado à base de conhecimentos da organização. No encerramento ocorre a entrega do produto com a conseqüente transferência de informações ao cliente do projeto. Após o encerramento é formada a memória técnica do 
projeto, com sua documentação. As informações e os conhecimentos adquiridos são incorporados à base de conhecimentos, o que vai agregar valor ao dia-a-dia da organização.

A inteligência empresarial, com o suporte de um sistema de informação empresarial, pode detectar a necessidade de realização de mudanças na organização. Para a efetivação destas mudanças são necessários projetos. Por sua vez, os projetos necessitam de informações para seu planejamento e para sua implementação. É aí que entra a gestão da informação. O papel da gestão da informação é fazer o monitoramento e também suprir a organização com informações de qualidade e no momento oportuno. A informação bem gerida conduz naturalmente ao aprendizado organizacional, desde que haja também a preocupação com a formação de uma base de conhecimentos da organização. Neste processo, a existência de projetos força uma busca por informações e também uma espontânea geração de informações com valor agregado, que também devem ser incorporadas à base de conhecimentos.

A inteligência empresarial, através do monitoramento ambiental, municia a gestão da informação com informações atualizadas. Por sua vez a gestão da informação também fornece informações para o monitoramento ambiental. Fluxo semelhante existe entre a gestão da informação e a gestão de projetos. Os projetos necessitam de informações da gestão da informação em seu início. Conforme ocorre seu desenvolvimento, o projeto também vai fornecendo informações com valor agregado à gestão da informação. A gestão da informação e a gestão do projeto vão fornecer insumos para a aprendizagem organizacional. Por último, com a aprendizagem organizacional consolidada através da base de conhecimentos, haverá disponibilidade de conhecimentos para uso, como por exemplo, em novos projetos.

Finalmente, levando em consideração tudo que foi exposto até este ponto, podemos apresentar um modelo conceitual cujo ponto central é a gestão da informação como ferramenta para tratamento e fornecimento/disponibilização de informações antes, durante e depois de um projeto. O modelo proposto é composto por quatro elementos: (a) a gestão da informação; (b) a gestão de projetos; (c) o ambiente para a aprendizagem e (d) a aprendizagem organizacional. O modelo proposto está representado esquematicamente pela FIG 2. 


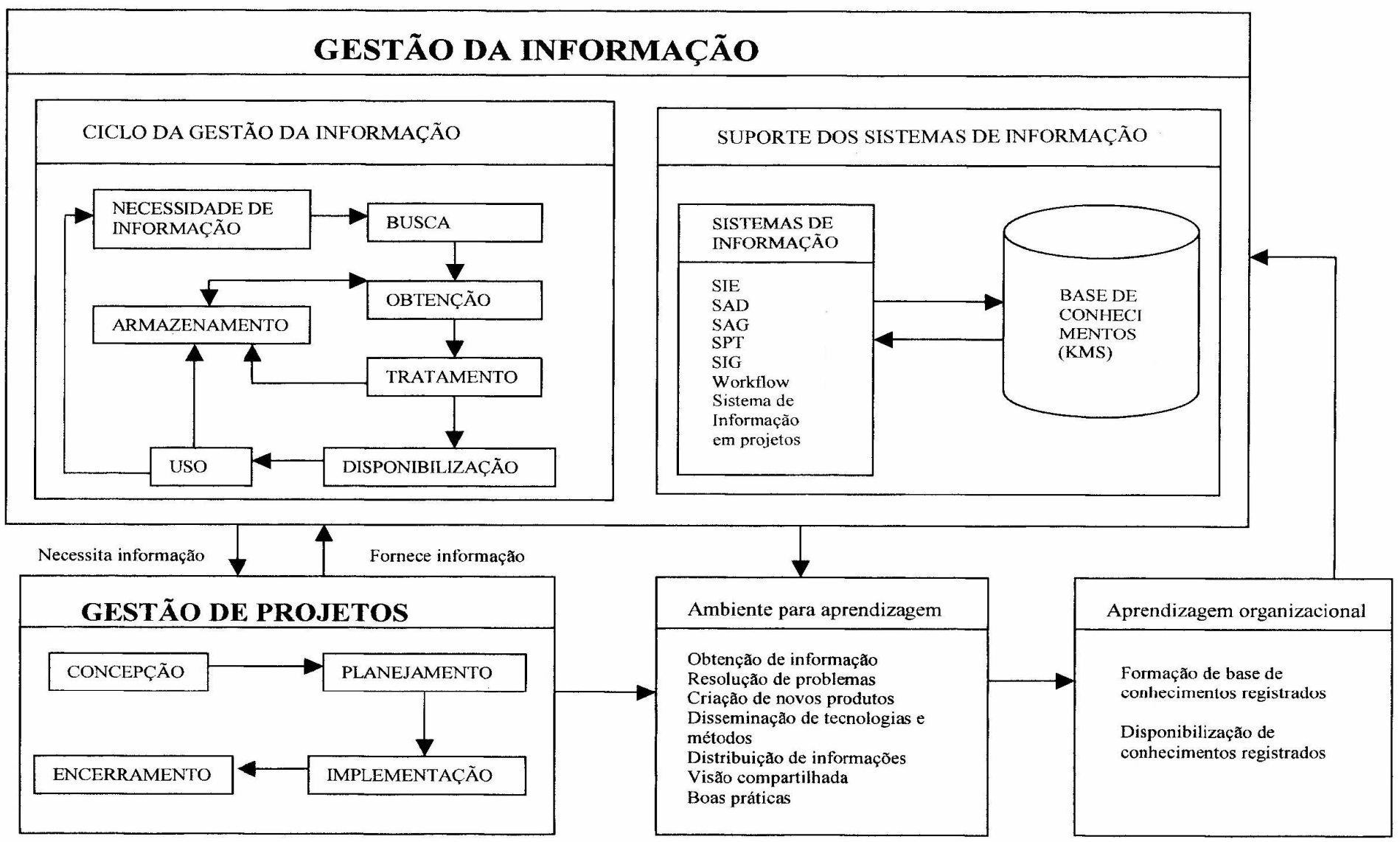

FIGURA 2 - Modelo de gestão da informação em gestão de projetos para aprendizagem organizacional.

Fonte: Dados da pesquisa.

Na seqüência faremos uma breve descrição do modelo.

Gestão da Informação: Tem o papel principal no atendimento das demandas por informação em termos de busca e obtenção, tratamento, armazenamento e disponibilização. A gestão da informação compreende o ciclo da gestão da informação com o suporte dos sistemas de informação.

Ciclo da gestão da informação: Parte de uma necessidade informacional para percorrer a busca e obtenção, tratamento, armazenamento, e disponibilização para uso, e retorna para o armazenamento ou determina uma nova necessidade de informação. Esses itens são descritos a seguir:

- Necessidade de informação: Assim que surge a idéia do projeto, os projetistas se sentem num estado anômalo devido à insuficiência ou a inadequação do conhecimento existente. $\mathrm{A}$ partir daí dispara uma demanda por informações ao gestor da informação na organização;

- Busca e obtenção: Recebendo a demanda, o gestor da informação parte para busca, nas diversas bases existentes, 
procurando acessar os estoques de informação, sempre com a preocupação da confiabilidade das fontes. Vale observar que as tecnologias de informação e comunicação agilizam a busca e a obtenção das informações necessárias. Um dos possíveis caminhos após a obtenção pode ser o armazenamento;

- Tratamento: Após a obtenção, as informações precisam ser depuradas, pois algumas delas não serão de utilidade. Após a depuração é dado o tratamento às informações selecionadas. Este tratamento compreende a atribuição de significado (interpretação), a contextualização, e a agregação de valor. Tratada a informação, ela pode ser armazenada ou disponibilizada de imediato aos projetistas;

- Disponibilização: De posse das informações adequadas às necessidades dos projetistas, o gestor da informação as torna disponíveis para uso. Vale ressaltar neste processo a necessidade de uma fácil recuperação da informação;

- Uso: O uso das informações disponibilizadas dá impulso ao projeto, porém as informações usadas não são consumidas. Por sua vez, o uso da informação pode conduzir a duas vertentes. A primeira diz respeito à possibilidade de produção de novas informações que devem ser incorporadas à base de conhecimentos da organização. A segunda se refere ao aparecimento de novas necessidades de informação dando, assim, reinício ao processo.

Suporte dos sistemas de informação: Estes sistemas visam a dar apoio em termos de facilitar e otimizar a obtenção, o tratamento, o armazenamento, recuperação/disponibilização e o uso das informações. Os principais sistemas informatizados em projetos são: sistema de informação empresarial (SIE); sistema de apoio à decisão (SAD), sistema de apoio a grupos (SAG), sistema de processamento de transação (SPT), sistema de informação gerencial (SIG), sistema de Workflow, sistemas específicos para projetos e o sistema de conhecimento.

Gestão de Projetos: Participa como um gerador de demanda por informações e também como um fornecedor de informação enquanto se desenvolve. As diversas etapas do projeto vão usando as informações disponibilizadas pelo gestor da informação e também vão gerando novas informações úteis que devem ser incorporadas à base de conhecimentos da organização.

Ambiente para aprendizagem: Diz respeito ao conjunto de atividades que ocorrem nos projetos que conduzem à aprendizagem organizacional. Estas atividades compreendem a obtenção de informação, a resolução de problemas, a criação de novos produtos, a transferência de tecnologias e métodos, a visão compartilhada, as boas práticas e a distribuição de informações.

Aprendizagem organizacional: Finalmente, com esta série de atividades desempenhadas e as inserções de informações, chega-se à formação de um conjunto de conhecimentos registrados, que vêm se 
juntar ao cabedal existente na organização. Todo este conjunto de conhecimentos registrados deve ficar à disposição da organização para uso em atividades rotineiras ou em novos projetos.

Importante destacar que a gestão da informação é uma atividade complexa que deve ser desempenhada por um profissional da informação em organizações de grande porte, de modo a aliviar a carga já extensa do gerente de projetos.

\section{Considerações finais}

Ao refletir sobre o tema aqui abordado, podemos deduzir algumas considerações.

Toda organização que pretende prosperar deverá lançar mão de projetos. Estes, por sua vez, não podem prescindir de informações bem geridas para que possam se tornar um sucesso. Portanto, a gestão da informação é um fator crítico de sucesso na gestão de projetos. Sem informação ou com informações mal geridas, maior o risco inerente ao projeto. As organizações precisam gerir informações de modo eficiente e eficaz, já que este é um insumo indispensável à sua sobrevivência. Assim precisam se preocupar com os processos de busca, produção, tratamento, armazenamento e disseminação das informações. A informação precisa fluir entre os membros da equipe do projeto e esta com os stakeholders. Por envolver uma intensa atividade de busca, reunião, interpretação, interação com o ambiente e uso de informações, o projeto gera um substancial aprendizado organizacional. Toda organização aprende, mas nem todas tiram proveito deste aprendizado. Para um bom aproveitamento do aprendizado organizacional é importante que a empresa adote processos de registros eficientes dos conhecimentos obtidos e dos produzidos. Além disso, estes conhecimentos devem ser disponibilizados para as pessoas certas, no momento necessário. Devido ao fato dos projetos se tratarem de empreendimentos destinados a alavancar as organizações, reconhecemos a importância estratégica das informações em projetos empresariais. O modelo aqui descrito não tem a pretensão de ser absoluto. Muito pelo contrário ele carece de experimentação e aperfeiçoamento, principalmente por se tratar de uma primeira abordagem desta natureza. A existência deste modelo é um primeiro passo na tentativa de possibilitar uma melhor gestão das informações em projetos por proporcionar uma visão de conjunto.

\section{Referências}

BARRETO, A. A. A questão da informação. São Paulo em Perspectiva, São Paulo, v. 8, n. 4, 1994. Disponível em: <http://www.eiasi.org/cinfor/quest/quest.htm>. Acesso em: 15 maio 2005.

BATISTA, E. O. Sistemas de informação: o uso consciente da tecnologia para o gerenciamento. São Paulo: Saraiva, 2004. 
CANONGIA, C. et al. Convergência da inteligência competitiva com construção de visão de futuro: proposta metodológica de sistema de informação estratégica (SIE). DataGramaZero - Revista da Ciência da Informação. v. 2, n. 3, jun. 2001. Disponível em: $<$ http://www.datagramazero.org.br/jun01/Art 02.htm $>$. Acesso em: 30 mar. 2006.

CAPURRO, R. Epistemologia e Ciência da Informação. In: ENCONTRO NACIONAL DE PESQUISA EM CIÊNCIA DA INFORMAÇÃO, V, 2003, Belo Horizonte. Disponível em <http://www.capurro.de/enancib p.htm $>$. Acesso em: 19 dez. 2005.

CARDOSO, L. H.; PEREIRA, E. C. Teoria do caos e gestão da informação: uma integração na complexidade dos negócios e dos sistemas de informação. Transinformação, Campinas-SP. v. 17, n. 3, p. 221-233, set/dez, 2005.

CHOO, C. W. A organização do conhecimento: como as organizações usam a informação para criar significado, construir conhecimento e tomar decisões. São Paulo: Senac, 2003.

DAVENPORT, T. H. Ecologia da informação. São Paulo: Futura, 2002.

FERREIRA, A. B. H. Dicionário Aurélio básico da língua portuguesa. São Paulo: c1988.

DINSMORE, P. C.; SILVEIRA NETO, F. H. Gerenciamento de projeto e o fator humano: conquistando resultados através das pessoas. Rio de Janeiro: Qualitymark, 2005.

FLEURY, A.; FLEURY, M.T.L. Aprendizagem e inovação organizacional: as experiências de Japão, Coréia e Brasil. São Paulo: Atlas, 1995.

GARVIN, D.A. Building a learning organization. Harvard Business Review, jul/aug., 1993 apud FLEURY, A.; FLEURY, M.T.L. Aprendizagem e inovação organizacional: as experiências de Japão, Coréia e Brasil. São Paulo: Atlas, 1995.

GARVIN, D. A. et al. Aprender a aprender. HSM Management, jul./ago. 1998. Disponível em <http://www.perspectivas.com.br/p8.htm >. Acesso em: 20 set. 2005.

KERZNER, H. Gestão de projetos: as melhores práticas. Porto Alegre: Bookman, 2002.

MAXIMIANO, A. C. A. Administração de projetos: transformando idéias em resultados. São Paulo: Atlas, 1997.

MCGARRY, K. O contexto dinâmico da informação. Brasília: Briquet de Lemos, 1999.

MORESI, E. A. D. O contexto organizacional. In: TARAPANOFF, $\mathrm{K}$. Inteligência organizacional e competitiva. Brasília: Editora da UnB, 2001(a). p. 59-91. 
MORESI, E. A. D. Monitoramento ambiental. In: TARAPANOFF, $\mathrm{K}$. Inteligência organizacional e competitiva. Brasília: Editora da UnB, 2001(b). p. 93-109.

MORESI, E. A. D. Gestão da informação e do conhecimento. In: TARAPANOFF, K. Inteligência organizacional e competitiva. Brasília: Editora da UnB, 2001(c). p. 111-142.

NONAKA, I.; TAKEUCHI, H. Criação de conhecimento na empresa. Rio de Janeiro: Campus, 1997.

PROJECT MANAGEMENT INSTITUTE - PMI-PMBOK. A guide to the project management body of knowledge. Newtown Square: PMI, 2004.

RABECHINI JR., R.; CARVALHO, M. M. Perfil das competências em equipes de projetos. RAE-eletrônica, São Paulo, v. 2, n. 1, jan-jun. 2003. Disponível em $<$ http://www.rae.com.br/eletronica/index.cfm?FuseAction=Artigo\&ID=133 $3 \&$ Secao $=$ OPERA/LOGI\&Voluma $=2 \&$ Numero $=1 \& A n o=2003>$. Acesso em: 06 abr. 2006.

REZENDE, D. A. Tecnologia da informação integrada à inteligência empresarial: alinhamento estratégico e análise da prática nas organizações. São Paulo: Atlas, 2002.

REZENDE, D. A.; ABREU, A. F. Tecnologia da informação: aplicada a sistemas de informação empresariais. São Paulo: Atlas, 2006.

SANTOS, R. N. M.; BERAQUET, V. S. M. Informação estratégica [1] e empresa: o discurso à prova dos fatos. DataGramaZero - Revista da Ciência da Informação, v. 2, n. 3, jun. 2001. Disponível em $<$ http://www.datagramazero.org.br/jun01/Art 01.htm>. Acesso em: 30 mar. 2006.

SAYÃO, L. F. Modelos teóricos em ciência da informação: abstração e método científico. Revista Ciência da Informação, Brasília, v. 30, n. 1, p. 82-91, jan./abr. 2001.

SILVA, J. F.; FERREIRA, M. A. T.; BORGES, M. E. N. Análise metodológica dos estudos de necessidades de informação sobre setores industriais brasileiros: proposições. Ciência da Informação, Brasília, v. 31, n. 2, p. 129-141, 2002.

TARAPANOFF, K. et al. Sociedade da informação e inteligência em unidades de informação. Ciência da Informação, Brasília, v. 29, n. 3, p. 91-100, set./dez. 2000.

VALERIANO, D. L. Gerência em projetos: pesquisa, desenvolvimento e engenharia. São Paulo: Makron Books, 1998. 